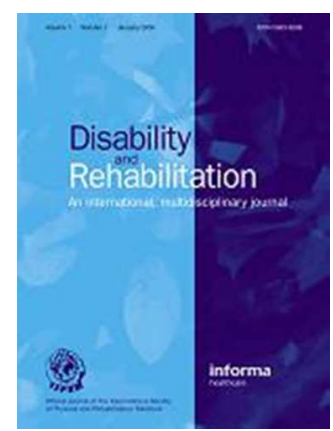

\title{
The feasibility, acceptability and preliminary efficacy of a low-cost virtual-reality based upper-limb stroke rehabilitation device: a mixed methods study
}

\begin{tabular}{|r|l|}
\hline Journal: & Disability and Rehabilitation \\
\hline Manuscript ID & TIDS-05-2017-025.R2 \\
\hline Manuscript Type: & Research Paper \\
\hline Keywords: & $\begin{array}{l}\text { gaming technologies; , stroke rehabilitation; , technology; , game-based } \\
\text { rehabilitation; , hemiplegia;, virtual reality }\end{array}$ \\
\hline
\end{tabular}

\section{SCHOLARONE \\ Manuscripts}


Implications for Rehabilitation

1. To ensure feasibility of use and maintenance of an appropriate level of challenge, gaming technologies for use in upper-limb stroke rehabilitation should be personalised, dependent on individual need.

2. Through use of hands-free systems and personalisation, stroke survivors with moderate and moderately-severe levels of upper-limb impairment following stroke are able to use gaming technologies as a means of delivering upperlimb rehabilitation.

3. Future studies should address issues of acceptability, feasibility and efficacy of personalised gaming technologies for delivery of upper-limb stroke rehabilitation in the home environment.

4. Findings from this study can be used to develop future games and activities suitable for use in stroke rehabilitation. 
Figure 1: Flowchart of recruitment, retention and study procedure

20 participants excluded

- 11 did not meet physical requirements

- 2 did not meet communication requirements

- 7 unable to meet attendance requirements

1 withdrawal prior to completion of intervention due to injury unrelated to the study

Post intervention assessment (T2) $n=11$

Measures of impairment, activity, participation, satisfaction with device and sense of presence. Semi-structured interviews

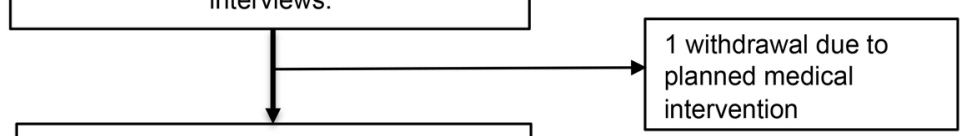

Follow-up assessment (T3) $n=10$

Measures of impairment, activity and participation wanned medical intervention

\author{
$157 \times 207 \mathrm{~mm}(300 \times 300 \mathrm{DPI})$
}




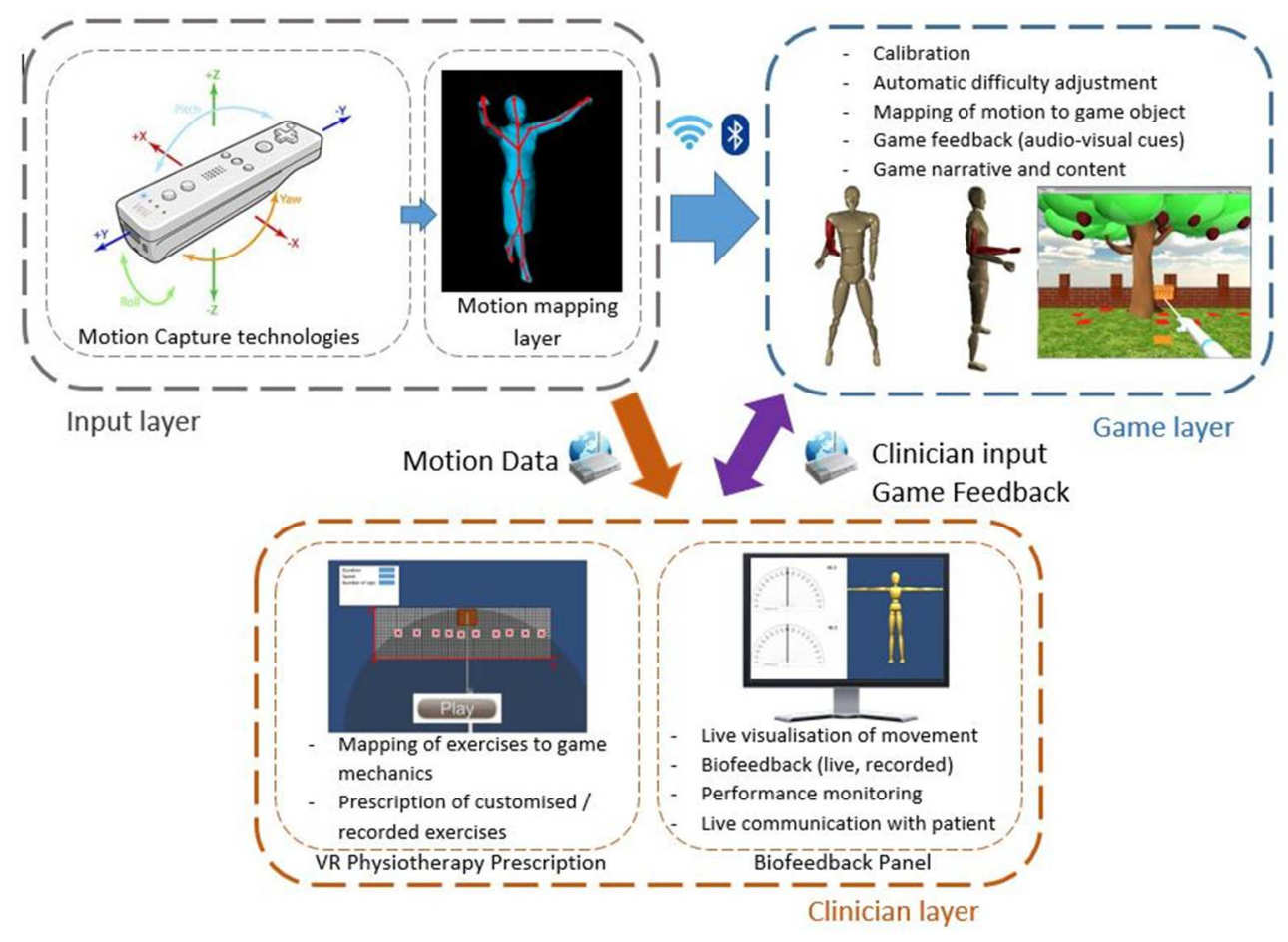

Figure 2: PST System Architecture

$189 \times 137 \mathrm{~mm}(120 \times 120 \mathrm{DPI})$ 


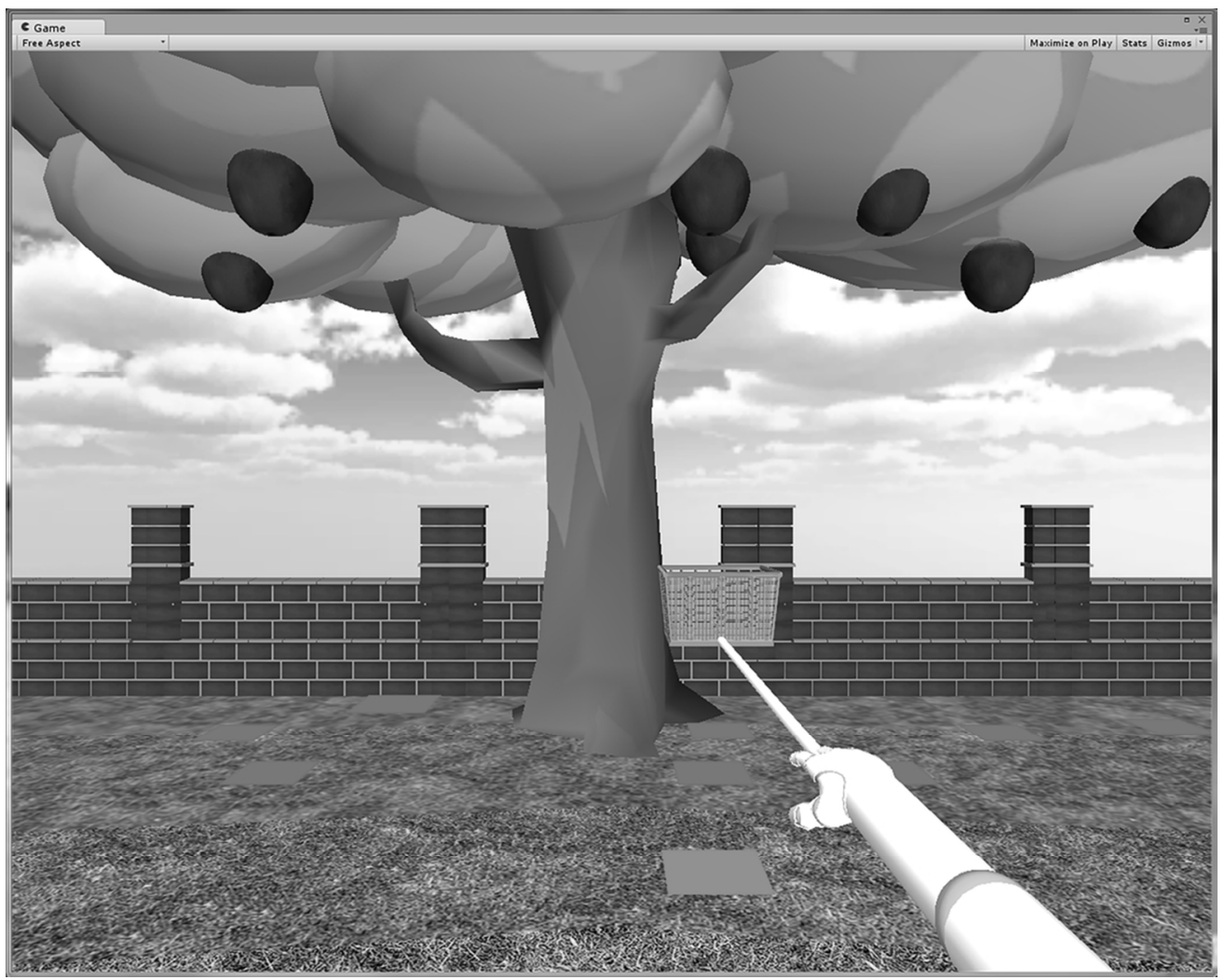

Figure 3: A screenshot of the apple-catching game $95 \times 76 \mathrm{~mm}(300 \times 300 \mathrm{DPI})$ 


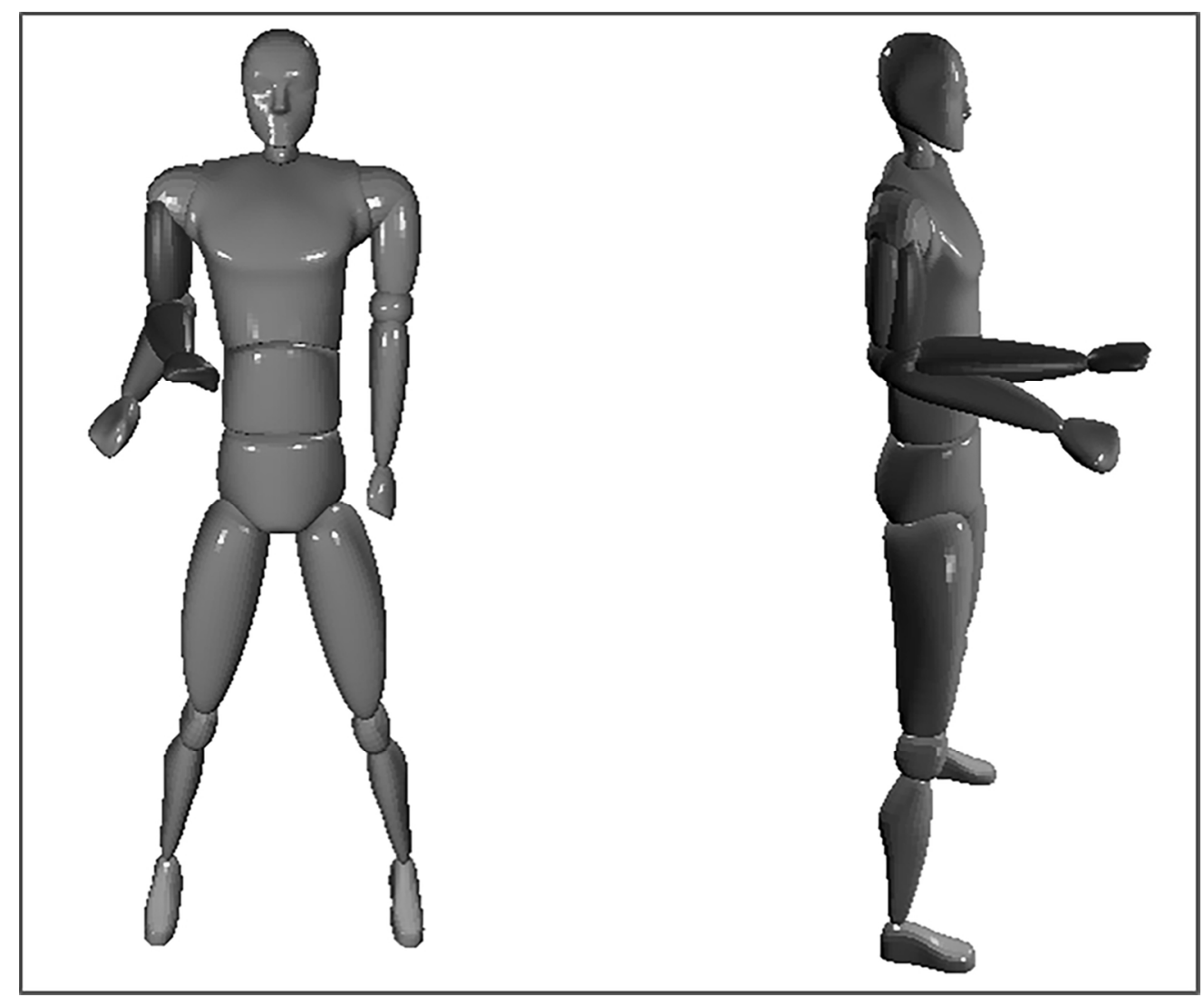

Figure 4: A screenshot of the virtual therapist application $99 \times 82 \mathrm{~mm}(300 \times 300 \mathrm{DPI})$ 


\section{Introduction}

Stroke is the leading cause of disability worldwide including the United Kingdom where over 100,000 strokes occur annually, resulting in an economic burden of $£ 9$ billion per year [1]. With improving survival rates and longer life expectancy in general, the burden of caring for stroke survivors is likely to increase [2, 3]. Eighty-five percent of stroke survivors will initially experience upper limb (UL) deficits [1] and of those with minimal movement on admission, only $11.6-14 \%$ regain full function $[4,5]$. As a lack of UL recovery results in significant dependence and a reduced quality of life, it has been found to be one of the strongest predictors of reduced psychological wellbeing following stroke, $[6,7]$. Effective UL treatment interventions have therefore been identified as a priority for stroke research [8].

Effective treatment interventions post stroke are characterised by high intensity and repetitive practice of a meaningful task [9]. In keeping with this, current guidelines recommend therapy sessions should be carried out for a minimum of 45 minutes daily for a minimum of five days a week [10]. However, changes in infrastructure, resource pressures [11], an emphasis on mobility during rehabilitation [12], a reduction in hospital length of stay [13] and a lack of therapy on discharge home have resulted in challenges delivering the amount of rehabilitation necessary to optimise recovery [ 1 , 14]. With demand for therapy outstripping available resources, there is a greater emphasis on stroke survivors exercising independently. However, adherence to such programmes is notoriously poor $[15,16,17]$. Lack of support, lack of feedback and boredom with exercises are the most frequently cited factors associated with poor adherence [12, 18, 19].

It has been suggested that the use of virtual-reality (VR) based activities can improve UL recovery following stroke through provision of a motivating treatment that 
is not reliant on increased therapist contact time $[20,21,22,23]$. The enjoyable and challenging nature of such activities may help address issues of boredom [12] and in addition, the ability to provide feedback may enhance motor learning [24, 25] and exercise adherence [26] and therefore help provide the high intensity, repetitious practice necessary to drive recovery [27]. Moreover, it has been postulated that the provision of visual feedback via an on-screen character (avatar) can activate 'mirror neurones' (brain cells involved in performing a movement which also "fire" when observing a movement) which has been suggested may aid recovery from stroke [28, $29,30,31]$.

While some bespoke and commercially available VR systems (such as GestureTek, IREX, CAREN, ARMEO) have been developed specifically for rehabilitation purposes, most are complex and beyond the financial scope of therapy departments. These costs and complicated set-up, are likely to limit feasibility and acceptability of use in the community [32]. Commercially available VR gaming technologies (such as the Nintendo Wii, Microsoft Kinect, Razer Hydra and Leap Motion) have become increasingly popular as motivating and relatively cheap alternatives [33, 34]. However, issues of acceptability and feasibility have been noted, particularly in those with more severe disability due to the large range of movement, coordination and speed required to play the games, the degree of coordination and dexterity necessary to use movement sensors and the demoralising effect of "negative" feedback $[35,36,37,38,39,40]$. As a result, some teams have adapted low-cost, commercially available VR gaming devices for use in rehabilitation [39, 40, 41, 42]. However, new therapies require thorough evaluation of efficacy, acceptability and feasibility of use prior to introduction into clinical practice $[32,38,43]$. 
Several systematic reviews have concluded that both commercially available and bespoke versions of VR systems are feasible to use and have positive effects on UL recovery following stroke, for those with moderate and mild UL deficits [38, 44, 45, 46, $47,48]$. Evidence in support of use in those with more severe disability is less convincing, with studies aiming to include those with moderate to severe UL impairments showing non-significant levels of improvement [48]. However, although protocols of some studies included in the review by Laver et al [48] allowed the inclusion of those with more severe UL deficits, in many cases it is not possible to ascertain the severity of those who actually participated and as such, the effectiveness with those with more severe deficits is unclear. Moreover, many studies inclusive of participants with moderate to severe UL impairments, have also employed the use of robotics or physical assistance from therapists in addition to VR, suggesting issues of feasibility of the systems when used alone and limited feasibility in the community [49, $50,51,52]$. While critical to exercise-adherence, few studies have considered patient evaluation of VR devices and when such evaluation has been performed, there has often been a lack of analytical rigour [38].

This paper builds on previous work $[35,39,53]$ outlining service-user, engineer and neuro-therapist involvement in the development of a low-cost, personalised stroke therapy (PST) system for UL rehabilitation following stroke, using an adapted version of a non-immersive commercially available VR gaming device. The PST system addresses several barriers identified in a previous stage of the study [35] including the use of a hands-free system, easier set up, greater accuracy and crucially, the ability to personalise activities with regard to range of movement, time played, sensitivity and speed. In this study, the concept of using adapted versions of commercially available VR gaming devices for delivery of UL rehabilitation was explored using the PST 
system. The primary objectives were to determine the feasibility (including safety) and acceptability of using the PST system for delivery of UL rehabilitation with community dwelling stroke survivors with differing levels of disability, including those with moderately-severe UL impairment. Although designed as a feasibility and acceptability study, a secondary aim was to examine preliminary estimates of the efficacy of the PST system.

\section{Methods}

\section{Design}

A mixed methods convergent study design was used, with separate quantitative and qualitative analyses followed by integration of the findings. Ethical approval for this study was granted by the Department of Clinical Sciences Research Ethics Committee, Brunel University (REC reference number 14/06/PHD/02). The principles of the Data Protection Act (1998) were adhered to throughout the study. The study sponsor was Brunel University.

\section{Recruitment}

Following recruitment presentations and use of poster advertisements at local stroke support groups, thirty-two people volunteered to participate in the study of which 12 fulfilled inclusion and exclusion criteria. In order to be more representative of the general stroke population and to address the lack of research focus on stroke survivors with more severe UL deficits, participants with mild to moderately-severe loss of UL function following unilateral stroke were included (score between 14-25 for both elbow and shoulder movement on the Motricity Index). Further inclusion criteria were adults who were a minimum of 12 weeks following stroke, had finished all formal UL 
rehabilitation, were able to sit independently for a minimum of five minutes, had the capacity to consent, understand and communicate in English and to follow instructions. Volunteers with pre-existing UL pain at rest, fixed contracture, active disease or orthopaedic conditions affecting the movement in the arm affected by stroke, photosensitive epilepsy, medical instability (such as uncontrolled angina), acquired brain injury from other causes, cerebellar lesions, pacemakers, visual neglect, hemianopias or uncorrected visual field deficits (score of 44 or below on the Star Cancellation Test) were excluded from the study. As travel burden has been identified as a barrier to research participation [54], pre-paid, wheelchair accessible taxis were offered to all participants to maximise recruitment. A flowchart detailing recruitment and retention of participants and study procedure is presented in figure 1.

\section{Insert Figure 1}

\section{The Personalised Stroke Therapy System}

The system adopted the holistic framework and system architecture proposed by Paraskevopoulos et al $[39,55]$ as depicted in Figure 2.

\section{Insert Figure 2}

The use of two Nintendo Wiimote wireless movement sensors, developed for use with the Nintendo Wii gaming console, enabled interaction between the system-user and the PST system. Movement data from the Wiimote sensors was sent to a computer using Bluetooth (wireless) technology and a data fusion algorithm [56] was used to combine and smooth data in order to achieve greater accuracy in movement tracking. This information was then mapped onto a three-dimensional body model. A game engine (Unity) (which has a free version) was employed to create a physical simulation of the 
PST system user by means of a 3D avatar which could be viewed on a computer screen.

The PST system used elastane pockets with hook and loop straps to secure movement sensors thereby allowing use by those unable to hold and operate the movement sensors. One sensor was secured on the lateral aspect of the upper-arm midway between the shoulder and elbow and the second was secured to the dorsal aspect of the forearm midway between the elbow and wrist.

Two activities (one game and one exercise), were used in the study. The applecatching game requires the system-user to practice shoulder, elbow and forearm movements in order to operate an onscreen arm to catch apples randomly falling from a tree (See Figure 3). Through the use of a therapist interface (see Figure 2), features such as player handedness, game duration, number of repetitions and the range of movement required to play the game can be altered by the therapist dependent on the system-user's ability. System-users are able to see their score and an encouraging message is provided at the end of each game (e.g. "well done", "keep going", "good effort"). In the virtual therapist application, functional movement patterns involving the shoulder, elbow and forearm are captured by recording the system-user performing these movements with facilitation from a therapist to ensure movements are challenging and functional. The recorded movement is mapped onto the arm of the virtual therapist and then played back on a loop (the duration of which is set by the therapist) at the same speed and range as the recording. System-users are instructed to follow the recorded virtual therapist arm (depicted in red in Figure 4) with their own arm (depicted in white in Figure 4). When system-user's movements match those of the virtual therapist, the onscreen arms are seen to blend together thereby providing instantaneous feedback. Insert Figures 3 and 4 here 


\section{Assessment}

Assessments of efficacy were conducted at baseline (T1), at one to five-days post completion of the intervention phase (T2) and at follow-up (T3) four weeks after completion of the intervention.

Information regarding acceptability and feasibility of the PST system was collected at T2 through semi-structured interviews performed by the lead researcher. As presence has been identified as a key issue affecting the effectiveness of VR devices [57], sense of presence in the virtual environment was examined using the iGroup Presence Questionnaire (IPQ) [58] at T2 (maximum score 84, with a higher score indicating a greater sense of immersion in the virtual environment).

During intervention sessions, participants rated their level of exertion and level of enjoyment for each activity immediately after cessation of each activity, using respectively, the 15-point Borg Scale of Perceived Exertion (rated from 6 to 20, with a higher score indicating a higher level of perceived exertion) and an 11-point visual analogue scale (VAS) (rated from 0 to 10, with a higher score indicating a higher level of enjoyment). Participants were monitored for adverse effects throughout the intervention. Incidences of pain were recorded and if incurred, severity was assessed using an 11-point VAS (from 0 to 10, with a high score indicating greater perception of pain). In addition, participants were assessed by the therapist to establish the nature of the pain and when required, the range of movement required for game-play was adjusted to avoid painful movements. Incidences of motion sickness were recorded and if incurred, severity was assessed using the 21-point FAST Motion Sickness Scale (from 0 to 20 , with a higher score indicating greater experience of motion sickness). Incidences of falls, near falls or other adverse effects were recorded on the intervention data collection form. 
Efficacy of the PST system was evaluated through examination of group changes in outcome measures between time-points. As no one measure is able to capture the differing effects of stroke $[59,60]$, different measures were employed to assess the efficacy of the PST system at all levels of the International Classification of Functioning, Disability and Health Framework (ICF) [61]. The upper extremity (motor, sensation, coordination and speed) sections of the Fugl-Meyer Assessment (FMA-UE) $[62,63]$ were used to assess impairment (scores between 0 and 70 with a higher number indicating a better performance). UL activity was assessed using the ABILHAND questionnaire [64] (scores between 0 and 69 with the higher score indicating better performance), Action Research Arm Test (ARAT) [65] (scores between 0 and 57 with a higher score indicating a better performance) and the Motor Activity Log -28 (MAL-28) [66] (scores between 0 and 5 with a higher number indicating better ability).

Participation was measured using the Subjective Index of Physical and Social Outcome (SIPSO) [67] (scoring is between 0 and 50 with a high score indicating a better level of integration).

To ensure standardisation of assessment, all researchers involved in assessment received training on the outcome measures being used, including training on the FMAUE as detailed by See et al [68] and in addition, a specific operations protocol was developed to ensure standardisation of assessment.

\section{Intervention}

The planned intervention consisted of nine, 40-minute exercise sessions using the PST system, delivered three days per week over three weeks. While mirroring a more realistic clinical picture, the requirement to attend only three days per week was chosen in order to aid recruitment, as more demanding protocols have been identified as a 
barrier to recruitment for trials involving physical activity [69]. To ensure consistency, all appointments were carried out on an individual basis in a university room using a standardised set-up imitating a typical living space.

Participants were required to exercise their hemiplegic arm under the direct supervision of a member of the research team (all of whom were qualified physiotherapists, experienced in stroke rehabilitation) using the apple-catching and virtual therapist applications. The supervising therapist set up and calibrated the system dependent on individual participant need, assisted participants to secure the Wiimote movement sensors and instructed participants regarding game-play and the avoidance of over-compensatory movements. Both activities were performed for a maximum of ten minutes and were then repeated. A minimum of two-minutes rest was incorporated between each of the four, ten-minute exercise blocks. Deviations from the protocol (for example when participants required more frequent or prolonged rests) and occurrences of adverse effects (such as pain) were recorded. Participants exercised in standing or sitting dependent on personal preference.

\section{Data Analysis}

Descriptive statistics are presented for quantitative data. Scores obtained on the FMAUE, ABILHAND, ARAT, MAL-28 and SIPSO were compared between T1 and T2, and T1 and T3, respectively, using Wilcoxon Signed Ranks. All analyses were performed using IBM SPSS version 20. In addition, change in individual scores between timepoints were compared with the minimally clinically important difference (MCID) where this had been established (FMA-UE, ARAT, MAL-28). Fieldwork notes and verbatim transcriptions of interview data were analysed using the six step Thematic Analysis phases recommended by Braun and Clarke [70]. The NVivo10 qualitative data software package (QSR International Pty Ltd. Version 10, 2012) was used to manage the data. 
While, a theme was identified when two or more participants discussed an issue, for brevity, one exemplar quote is used for each point raised. Side by side joint displays as recommended by Creswell [71], were used to integrate findings from quantitative and qualitative arms of the study. Initial analysis was undertaken by the lead researcher, with validation of qualitative findings through discussion and review of themes with a second member of the research team who is an experienced qualitative researcher (CK).

\section{Results}

Twelve community dwelling stroke survivors ( 9 female) aged between 48 and 68 years (mean (SD) 58 (7.1) years) were recruited to the study. Stroke chronicity was between 12 and 304 months (median (IQR) 42 (34.7) months) and participants were classified as having slight to moderately-severe stroke severity (between 2 and 4 on the Modified Rankin Scale). Participant details (using pseudonyms) are presented in table 1.

\section{Insert table 1}

One participant (George) dropped out prior to follow-up (T3), due to medical intervention unrelated to the study and was therefore not included in statistical analysis at T3 but is included in analysis at other assessment points. A further participant (Nell) dropped out during the intervention phase due to injury unrelated to the study, and was therefore not included in analysis at T2 and T3. For ten participants, each assessment was undertaken by a different researcher who was blind to previous assessment scores. Due to staffing issues, one participant (George) was assessed by the same researcher at $\mathrm{T} 1$ and $\mathrm{T} 2$.

Integrated findings regarding feasibility (including safety), acceptability and efficacy of the PST system are presented in tables 2 to 4 respectively. The term "QN" indicates a quantitative finding, "QL" refers to a qualitative finding and the number corresponds to where the findings (including exemplar quotes) can be found in the results tables. 


\section{Insert table 2-4 here}

Thirteen adverse effects were experienced by five participants (QN1 table 2). The mean time using the PST system was 276 minutes (standard deviation 64.3; range 175 to 336 mins) out of a target of 360 minutes (QN2 table 2). The discrepancy between target duration and achieved duration was due to late attendance at the sessions because of travel delays and participant fatigue. Participants reported high levels of enjoyment for both activities (QN4 \& 5 table 3) and average rating of perceived exertion (RPE) was "fairly light" and "somewhat hard" for the apple-catching game and virtual therapist application, respectively (QN6 \& 7 table 3). Scores on each outcome measure at each time-point are presented in Table 5.

Insert table 5 here

\section{Discussion of Integrated Findings}

\section{The PST system was safe to use}

As with other VR gaming studies [48] there was strong agreement between quantitative and qualitative findings that the PST system was safe to use, with adverse effects being infrequent and when occurring, mild in nature (QN1, QL1 \& 2 table 2). While UL pain was experienced by five participants (QN1 table 2), it was mainly associated with unaccustomed muscular activity and was described by participants as a "good pain" (QL1 table 2) and evidence of intensity of practice as opposed to a true adverse effect. Two participants experienced pain consistent with shoulder soft tissue impingement (QN1 table 2) possibly as a result of disparity between the participant's actual motor ability and the task demands. Pain stopped on cessation of the activity and did not reoccur once the range of movement was adjusted to avoid painful movements (again supporting the need for personalisation of activities with regard to the range of 
movement required). Similar to findings by Lewis et al [72] and Thomson et al [34] fatigue (QL2 table 2) was noted but was again considered by participants as an indication of intensity of use.

\section{The PST system was feasible to use}

The PST system was felt to be intuitive to operate without the need for extensive instructions (QL3 table 2), and all participants were able to use the system (QN2 table 2). Critically, the ability to personalise activities depending on individual need and the use of a hands-free system (QL4 table 2) also enabled use by participants with moderately-severe disability without the need for orthoses or additional help (QL5 table 2). The average RPE for the virtual therapist application as "somewhat hard" (QN7 table 3) was echoed in the qualitative data (QL11 table 3). However, while the average RPE for the apple catching game was "fairly light" (QN6 table 3), a theme of considerable effort was apparent in the qualitative data (QL11 table 3). This apparent discrepancy may be a result of differences in the selection of the movement range required to play the apple-catching game as several participants spoke of one researcher (the lead researcher) setting parameters that made game play much harder in comparison to the second researcher (QL13 table 3). The findings of effort associated with the virtual therapist application and the apple-catching game (when set up by the lead researcher) suggest that through personalisation of the range of movement, speed, and duration of activities, the PST system was able to maintain the level of challenge for those with a wide range of impairments following stroke. There was strong agreement between data sets that the apple-catching game was the easier task (QN6, QL11 table 3) and in line with this, participants with milder stroke severity identified a need for a faster speed of the falling apples (QL12 table 3) suggesting the need for 
further personalisation. This was not a theme in those with more severe disability indicating the slower speed was appropriate for those participants.

Similar to other studies $[36,40]$, the use of the hands-free system was essential for the majority of participants in the present study, several of whom had been unable to use the hand-held movement sensors when they had tried to use VR gaming technologies in the past (QL4 table 2). However, field notes showed that only two participants were able to attach the movement sensors themselves, thereby limiting feasibility of independent set-up (QL7 table 2).

\section{Lack of confidence with technology is a barrier to use}

Confidence with technology was not assessed quantitatively, however, in support of findings by Wingham et al [36], a theme of a lack of confidence with technology, was recognised as a potential barrier to use in the qualitative data (QL6 table 2). The lack of confidence suggested the need for initial support and the need for technology which is simple to set up and use to enable independent use.

\section{The PST system was a source of motivation}

In support of findings from other VR based rehabilitation studies $[36,72,73]$ overall, high levels of enjoyment when using the PST system were apparent in both quantitative and qualitative data, suggesting a high degree of acceptability of use $($ QN4 \& 5, QL8, 9 \& 19 table 3). A theme of the virtual therapist being like "boring, repetitive physio" was expressed by participants with more severe levels of disability (QL10 table 3) and was supported by lower ratings of enjoyment in the quantitative data (QN5 table 3). However, a highly prevalent theme of fun was associated with the apple-catching game by all participants (QN4, QL9 table 3), and was related to a feeling of "time flying" 
(QL8 table 3). The concept of time flying is said to be positively correlated with enjoyment [74], with time seeming to pass more rapidly with enjoyable activities [75] and slower with less enjoyable ones [76]. This distortion in the perception of time is associated with the concept of "flow", that is the "optimal experience" and high level of enjoyment that is said to occur when immersed in a goal directed task, which is both challenging yet perceived to be within one's ability $[77,78]$. High ratings of level of enjoyment (QN4 table 3) and the theme of time flying (QL8 table 3) suggests that participants achieved a state of flow when using the PST system, thereby helping address the issue of boredom experienced with traditional therapy (QL10 table 3, QL31 table 4) and suggesting the PST system has the ability to motivate and help deliver the intensity of practice necessary to drive change.

There was strong agreement between data sets that the virtual therapist was the more strenuous activity $($ QN6 \& 7, QL11 \& 14 table 3). As flow is said to be greatest when level of effort and challenge, matches ability $[79,80]$ the preference for the apple-catching game in those with more severe stroke and preference for the virtual therapist application with those with milder strokes (QL14 table 3) (in spite of being rated as less fun) (QN4 \& 5 table 3) may therefore be related to the level of challenge experienced. This again highlights the necessity of personalisation of rehabilitation activities.

\section{More feedback is required from the virtual teacher application}

In addition to the level of challenge (QN6, QL11 \& 14 table 3), the higher rating of enjoyment with the apple-catching game may relate to the game-like characteristics inherent in its design, as all participants discussed the motivational effects from having a score to beat and a star reward system to improve upon (QL15 table 3). Moreover, a 
need for increased feedback to maintain motivation was identified (QL16 table 3) and this may have contributed to the lower rating of enjoyment for the virtual teacher application. This supports findings from other studies of VR in stroke rehabilitation where the motivational effects of feedback and having a score to beat were also noted [69]. In keeping with conclusions drawn by Cristea and Levin [81] the need for increased feedback with regard to how to improve (so called knowledge of performance) was also noted (QL15 table 3). As intrinsic (internal) feedback mechanisms may be damaged following stroke, there is a greater reliance on feedback from an external source (so called, extrinsic feedback) [82]. The preference for the apple-catching game observed in participants with more severe strokes may therefore be linked to the greater amount of extrinsic feedback provided by the apple-catching game, while those with milder strokes were potentially more capable of using intrinsic feedback to identify and correct their own mistakes $[81,83]$.

\section{Telerehabilitation: An opportunity for additional support and feedback or Big}

\section{Brother?}

When asked directly about the concept of using VR gaming devices as part of telerehabilitation, a strong theme of acceptance was apparent in the qualitative data with all participants stating they would want to use such a device (QL21 table 3). The ability of the therapist to monitor exercise was strongly associated with increased exercise adherence (QL31 table 4) and was viewed as an opportunity to receive feedback on performance and a feeling of support, which have been identified as critical in rehabilitation [12]. However, as well as a lack of confidence with technology (QL6 table 3) two participants expressed a mild concern that others may be worried by the intrusive, "Big Brother" nature of telerehabilitation, suggesting issues of acceptability with some (QL21 table 3). 


\section{Efficacy of the PST system}

While, no participant achieved the targeted intervention time (QN2 table 2), nonetheless, the PST system appeared to be an efficacious device for UL rehabilitation in this cohort of stroke survivors (QN8-10, QL26, $27 \& 29$ table 4, table 5). There was evidence of improvement in all measures of impairment, activity and participation between T1 to T2 (QN8-10 table 4) (p value $<0.05$ for all) and clinically important changes in impairment and activity between T1 and T2 (QN8-9 table 4). These findings were supported by prevalent subthemes of improvements in (physical and psychological) impairment and activity generated from qualitative data $($ QL26, $27 \& 29$ table 4). Interestingly, while there was evidence from quantitative data that improvements were maintained at the impairment level between $\mathrm{T} 1$ to $\mathrm{T} 3(\mathrm{p}=0.033)$ (QN8 table 4), there was no evidence that improvements were maintained in measures of activity and participation (QN9 \& 10 table 4). These findings suggest that the dosage of therapy may be insufficient to sustain changes in activity and participation and support findings by Teixeira-Salmela et al [84] who noted improvements in activity and participation required higher doses of intervention compared to improvements at an impairment level.

While increased participation in society following PST system use was not a theme in the qualitative data, the ability to play against someone on-line by people with impaired communication (QL17 table 3) and the motivational aspects of playing against family members (QL18 table 3), suggested VR gaming devices could potentially promote socialisation. However, as concerns about the level of competition were raised (QL20 table 3), such programmes would potentially need to incorporate an "equalising" feature system to ensure equity between players. 


\section{Possible mechanisms in recovery}

Qualitative data suggested possible mechanisms of recovery namely the ability of the PST system to deliver intensity of practice (QN4 \& 5, QL8, 9 \& 11 table 3), to address learnt non-use (QL27 table 4) and activate mirror-neurones (QL30 table 4).

Themes of enjoyment (QN4, \& 5, QL8 \& 9 table 3) and motivation to exercise (QL15 table 3 \& QL29 table 4) associated with the PST system, suggested the potential of such gaming technologies to be used as instruments to address barriers to rehabilitation identified when participants discussed their previous experience of rehabilitation. These barriers included resource issues of "too many patients" (QL22 table 3), a "focus on legs" and walking at the expense of the upper limb (QL23 table 3), "wasted time in rehabilitation" (QL24 table 3) boredom and therefore poor adherence with traditional exercise (QL31, 32 \& 34 table 4), the prescription of exercises that were too difficult (QL33 table 4) and a feeling of being abandoned on discharge (QL25 table 3). Neuroplastic change is unlikely to have occurred with the intervention dose provided in the present study $[21,48,84]$. Although the system was non-immersive in nature (confirmed by low ratings of immersion on the IPQ and relative silence in the qualitative data) (QN11, QL30 table 4), none -the-less, the possibility of mirror neurone activation cannot be ruled out as observation of movements combined with physical practice has been associated with improved physical performance $[31,85,86]$. It is probable that physical improvements noted in both sets of data (QN8-10, QL26-29 table 4), were due to increased motivation to try and use the affected limb and spontaneous functional use (QL27 table 4). In addition, the psychological effects of renewed hope in UL recovery as a result of the study intervention (QL29 table 4) suggested increased motivation to try and use the arm in functional tasks. Finally, 
although not a theme in the data, improvements seen may be related to greater use of compensatory strategies.

\section{Study Strengths and Limitations}

The use of mixed methods, integrating quantitative results and qualitative findings provided extra data and greater insight into phenomena and has been advocated as a "powerful tool" to explore complex issues in healthcare $[82,83]$ and is a strength of this study. In addition, areas of high agreement between the data sets, strengthened the validity of findings and where they differed, qualitative findings provided possible explanations for results found. Moreover, the use of both quantitative and qualitative methods allowed the strengths of both types of study to off-set the methodological weaknesses inherent in the other [68].

The multi-disciplinary nature of the development team (including stroke survivors, engineers, designers and neuro physiotherapists) ensured the PST system included features known to be important for recovery and those likely to result in greater engagement. In addition, while the inclusion of participants with communication difficulties and mild cognitive problems in this study resulted in less data and therefore a reduced presence in the qualitative analysis, recruitment of such participants is recommended nonetheless as being more representative of the stroke population and moreover provided additional insights into the way technology can be useful (QL17 table 3). Additionally, the ability to personalise the PST system and interventions resulted in the inclusion of those with moderately-severe UL deficits. While those with mild to moderate UL deficits have other effective rehabilitation options available to them, such as simple recreational activities [89] and traditional therapy exercises, the options for those with more severe deficits are limited. Of the few studies which have 
included participants with more severe deficits, most have required additional support (from a therapist or an orthosis) to enable use thereby limiting feasibility in the community [49]). Although some UL movement to use the PST system was required (thereby limiting use in those with severe disability), the use of a hands-free system and the ability to individually calibrate activities ensured that those with moderately-severe disability were able to use the system. Furthermore, the comparison between a therapytype activity and a game provided greater insight into factors affecting acceptability and provided greater direction for future developments for VR based rehabilitation.

A number of study limitations were apparent and results must therefore be interpreted with caution. The study was primarily designed to examine issues of feasibility and acceptability and was not specifically designed to look at efficacy. As the study was underpowered without a control group it is impossible to determine if changes in impairment, activity and participation were due to the intervention or other factors such as familiarity with tests over time. Further, the absence of evidence of changes in some outcomes over time may be due to the small sample. Lack of blinding and use of a convenience sample may have also resulted in a biased estimate of the effect of the intervention.

Although participants were reminded at the start of the interview of the importance of giving responses that truly reflected their experiences, (i.e. the good and the bad), the use of the lead researcher as interviewer may have precipitated more positive responses from study participants all of whom were aware of the study purpose and role of the lead researcher. The use of an interviewer unknown to the participants although preferable, was not possible within the confines of a time and funding limited study. The use of the lead researcher in the coding of data and development of themes was a further methodological limitation and may be associated with inadvertent bias in 
development of themes. To help address biases, reflective field-notes and regular engagement with the supervisory team to enhance criticality and challenge assumptions was undertaken.

The PST system was not feasible to use with all stroke-survivors. Of the 32 study volunteers, eleven were excluded on physical grounds likely to preclude use of the system. While feasibility of using video gaming technologies for rehabilitation is likely to be limited in those with UL pain and photosensitive epilepsy (experienced by 3 and 2 volunteers respectively in the present study), the exclusion of those with very mild and severe impairments (experienced by 6 volunteers), suggests the need for further personalisation to allow use by stroke survivors with different levels of UL impairment. Finally, the use of researchers to subjectively set game-play features, (such as the range of movement required to complete activities) and the inability to adjust speed of the falling apples in the apple-catching game, resulted in a disparity in the level of challenge experienced by some participants.

\section{Recommendations for Future Research}

To ensure optimal practice conditions and use by stroke survivors with differing levels of ability, it is recommended that future studies should employ hands-free gaming technologies with automatic calibration and the ability to be personalised with regard to speed, duration of play, range of movement, task complexity and type and amount of feedback. The efficacy of such systems (including any differences between games versus exercise applications) should be examined through the use of more robust methods such as randomised controlled trials.

The move towards home-based rehabilitation suggests that future studies should address acceptability (including exploration of barriers to uptake of new technology), 
feasibility (including set up) of VR gaming technology in home environments and effectiveness of such systems on long term exercise adherence.

As immersion has been linked with improved efficacy [90] future studies using VR gaming technology should consider using more immersive technologies where feasible. However, this must be balanced with the financial considerations and ease of use as high costs and complicated set-up are likely to make use of such systems prohibitive [32]. A limitation of the present study inherent in all studies using gaming technology, is the risk of redundancy with tested devices rapidly being superseded by advances in technology. It is therefore critical that devices and activities can quickly and easily be adapted for continued use in rehabilitation on different operating platforms and that such developments remain attractively priced.

Finally, as the study was designed as an acceptability and feasibility study, further research into the efficacy of the PST and similar systems particularly in those with more severe disability is warranted.

\section{Conclusion}

In summary, results from this mixed-methods study found high levels of acceptability and feasibility of use a VR based system using adapted commercial gaming technology as a method to deliver UL rehabilitation in a group of community dwelling stroke survivors. Feasibility of use was associated with the use of a hands-free system and the ability to personalise activities depending on individual needs and enabled use by participants with moderately-severe UL deficits, in whom there is a recognised difficulty in provision of suitable exercise [12]. Acceptability was linked to enjoyment, feedback, physical and psychological benefits experienced and the perceived ability to address a number of barriers to rehabilitation including a lack of therapy, reduced motivation and poor adherence to out of session exercise programmes. The results of 
the study also indicated that such systems may improve impairment, activity and participation among stroke survivors in the short-term.

Crucially, while fast-moving technological advances can result in redundancy in such systems, results from the present study demonstrate the feasibility and acceptability of the concept of using bespoke VR gaming activities as a means to deliver stroke rehabilitation. In addition, findings can be used to develop future games and activities suitable for use in stroke rehabilitation.

\section{References}

1. Stroke Association. State of the Nation Stroke Statistics [Internet] 2016 Jan. [cited 2017 Feb 16]: Available from:http://www.stroke.org.uk/resource-sheetnation-stroke-statistics.

2. McHugh G, Swain ID, Jenkinson D. Treatment components for upper limb rehabilitation after stroke: a survey of UK national practice. Disabil Rehabil. 2014;36(11):925-931.

3. Hughes A, Burridge J, Demain S, Meagher C, Tedesco-Triccas L, Turk R et al. Translation of evidence-based assistive technologies into stroke rehabilitation: users' perceptions of the barriers and opportunities. BMC Health Serv Res. 2014; 14:124.

4. Nakayama H, Jorgensen H, Raaschou H, Olsen T. Recovery of upper extremity function in stroke patients: the Copenhagen Stroke Study. Arch Phys Med Rehabil. 1994;75:394-398.

5. Kwakkel G, Kollen B, van der Grond J, Prevo A. Probability of regaining dexterity in the flaccid upper limb: impact of severity of paresis and time since onset in acute stroke. Stroke. 2003;34:2181-2186..6

6. Nichols-Larsen DS, Clark PC, Zeringue A, Greenspan A, Blanton S et al. Factors influencing stroke survivors' quality of life during subacute recovery. Stroke. 2005;36(7):1480-4.

7. Wyller TB, Sveen U, Sodring KM, Petterson A, Bautz-Holter E. Subjective well-being one year after stroke. Clin Rehabil. 1997;11(2):139-45.

8. Rankin G, Rushton A, Olver P, Moore A. Chartered Society of Physiotherapy's identification of national research priorities for physiotherapy using a modified Delphi technique. Physiother. 2012;98(3):260-272.

9. Langhorne P, Coupar F, Pollock A. Motor recovery after stroke: a systematic review. Lancet Neurol. 2009;8:741-754.

10. NICE. Stroke rehabilitation in adults [Internet] 2013 [cited 2016. Nov.10]; available from: http://www.nice.org.uk/guidance/CG162

11. CSP. A new ambition for stroke. A consultation on national response strategy response from the Chartered Society of Physiotherapy. London: CSP; [Internet] 2007. [cited 2017.April.11]; available from: http:www.csp.org.uk/pressreleases/200712/05/csp-responds-new-department-health-stroke-strategy 
12. Barker R, Brauer S. Upper limb recovery after stroke: the survivors' persepective. Disabil Rehabil. 2005;27(20):1213-1223.

13. Department of Health. National Stroke Strategy. London; Department of Health; 2007.

14. McHugh G, Swain ID. A comparison between reported and ideal patient-totherapist ratios for stroke rehabilitation. Health. 2013;05(06):105-112.

15. Donoso Brown EV, Dudgeon BJ, Gutman K, Moritz C, McCoy S. Understanding upper extremity home programs and the use of gaming technology for persons after stroke. Disabil Health J. 2015;8(4):507-13.

16. Jurkiewicz M, Marzolini S, Oh P. Adherence to a home-based exercise program for individuals after stroke. Top Stroke Rehabil. 2014;18(3):277-284.

17. Hendrie W. The dog ate my trainers. Synapse. 2011;25:24.

18. Disler P, Wade D. Should all stroke rehabilitation be home based? Am J of Phys Med Rehabil. 2003;82:733-735.

19. Hung YX, Huang PC, Chen KT, Chu W. What Do Stroke Patients Look for in Game-Based Rehabilitation: A Survey Study. Medicine. 2016; 95(11):e3032. doi: 10.1097/MD.0000000000003032. PubMed

20. Turolla A, Dam M, Ventura L, Tonin P, Agostini M, Zucconi C et al. Virtual reality for the rehabilitation of the upper limb motor function after stroke: a prospective controlled trial. J Neuroeng Rehabil. 2013;10(1),85.

21. Veerbeek JM, van Wegen R, van Peppen R, van der Wees P, Hendriks E, Rietberg M. What is the evidence for physical therapy post stroke? a systematic review and meta analaysis. Plos ONE. 2014;9(2):e87987 1-83. doi: 10.1371/journal.pone.0087987

22. Laver K, George S, Thomas S, Deutsch J, Crotty M. Virtual reality for stroke rehabilitation [systematic review ]. Cochrane Database of Syst Rev. 2015(2):1107. doi.10.1002/14651858.CD008349.pub.3

23. Ballester BR, Maier, M, San Segundo R, Galeano VC, Duff A, Verschure PF. Reinforcement-Induced Movement Therapy: A novel approach for overcoming learned non-use in chronic stroke patients. Proc. Intl Conf. Virtual Rehabilitation (ICVR), 2015. IEEE.183-190.

24. Subramanian SK, Lourenco CB, Chilingaryan G, Sveistrup H, Levin M. Arm motor recovery using a virtual reality intervention in chronic stroke: randomized control trial. Neurorehabil Neural Repair. 2013:27(1):13-23. doi: $10.1177 / 1545968312449695$

25. Kiper P, Piron L, Turolla A, Stoźek J, Tonin P. The effectiveness of reinforced feedback in virtual environment in the first 12 months after stroke. Neurologia $i$ Neurochirurgia Polska. 2011;45(5):436-444. doi: 10.1016/s00283843(14)60311-x.

26. Peek K, Sanson-Fisher R, Mackenzie L, Carey M. Interventions to aid patient adherence to physiotherapist prescribed self-management strategies: a systematic review. Physiother. 2016;102(2):127-35. doi: 10.1016/j.physio.2015.10.003.

27. Kwakkel G, Kollen B, Lindeman E. Understanding the pattern of functional recovery after stroke: facts and theories. Restor Neurol Neurosci. 2004;22:28199.

28. Franceschini M, Ceravolo MG, Agosti M, Cavallini P, Bonassi S, Dall'Armi V et al. Clinical relevance of action observation in upper-limb stroke rehabilitation: a possible role in recovery of functional dexterity. A randomized clinical trial. 
Neurorehabil Neural Repair. 2012;26(5):456-62. doi:

$10.1177 / 1545968311427406$

29. Pekna M, Pekny M, Nilsson M. Modulation of neural plasticity as a basis for stroke rehabilitation. Stroke. 2012;43(10):2819-28. doi:

10.1161/STROKEAHA.112.654228.

30. Celnik P, Stefan K, Hummel F, Duque J, Classen J, Cohen L. Encoding a motor memory in the older adult by action observation. Neuroimage.

2006;15;29(2):677-84. doi: 10.1016/j.neuroimage.2005.07.039.

31. Ertelt D, Small S, Solodkin A, Dettmers C, McNamara A, Binkofski F et al. Action observation has a positive impact on rehabilitation of motor deficits after stroke. Neuroimage. 2007;36 Suppl 2:T164-73. doi:

10.1016/j.neuroimage.2007.03.043.

32. Scherer MJ. Technology adoption, acceptance, satisfaction and benefit: integrating various assistive technology outcomes. Disabil Rehabil Assist Technol. 2017;12(1):1-2. doi: 10.1080/17483107.2016.1253939.

33. Ravenek KE, Wolfe DL, Hitzig SL. A scoping review of video gaming in rehabilitation. Disabil Rehabil Assist Technol. 2015;27:1-9. doi: 10.3109/17483107.2015.1029538. PubMed PMID: 25815680.

34. Thomson K, Pollock A, Bugge C, Brady M. Commercial gaming devices for stroke upper limb rehabilitation: a survey of current practice. Disabil Rehabil Assist Technol. 2016;11(6):454-61. doi: 10.3109/17483107.2015.1005031.

35. Warland A, Kilbride C, Tsekleves E, Skordoulis D, Paraskevopoulos I. ReWiiRe (Research in Wii Rehabilitation): User involvement in the development of a personalised rehabilitation system for arm re-education after stroke. Intl J Stroke. 2012; Vol 7 (Suppl. 2); :27.

36. Wingham J, Adie K, Turner D, Schofield C, Pritchatd C. Participant and caregiver experience of the Nintendo Wii Sports after stroke: qualitative study of the trial of Wii in stroke (TWIST). Clin Rehabil. 2015;29(3):295-305. doi: $10.1177 / 0269215514542638$.

37. Joo LY, Yin T, Xu D, Thia E, Chia P, Kuah C et al. A feasibility study using interactive commercial off-the-shelf computer gaming in upper limb rehabilitation in patients after stroke. J Rehabil Med. 2010;42(437-441).

38. Thomson K, Pollock A, Bugge C, Brady M. Commercial gaming devices for stroke upper limb rehabilitation: a systematic review. Intl J Stroke. 2014;9:479488.

39. Tsekleves E, Paraskevopoulos I, Warland A, Kilbride C. Development and preliminary evaluation of a novel low cost VR-based upper limb stroke rehabilitation platform using Wii technology. Disabil Rehabil: Assist Tech. 2016;11(5):413-422. doi: 10.3109/17483107.2014.981874.

40. Teo WP, Muthalib M, Yamin S, Hendy A, Bramstedt K, Kotsopoulos E et al. Does a Combination of Virtual Reality, Neuromodulation and Neuroimaging Provide a Comprehensive Platform for Neurorehabilitation? - A Narrative Review of the Literature. Front Hum Neurosci. 2016;10:284. doi: 10.3389/fnhum.2016.00284.

41. Lange B, Koenig S, Chang CY, McConnell E, Suma E, Bolas M et al. Designing informed game-based rehabilitation tasks leveraging advances in virtual reality. Disabil Rehabil. 2012;34(22):1863-70. doi: 10.3109/09638288.2012.670029.

42. Bower K, Louie J, Landersrocha Y, Seedy P, Gorelik A, Bernhardt J. Clinical feasibility of interactive motion-controlled games for stroke rehabilitation. J Neuroeng Rehabil. 2015;12(63). doi: 10.1186/s12984-015-0057-x. 
43. Craig P, Dieppe P, MacIntyre S, Michie S, Nazareth I, Peticrew M. Developing and evaluating complex Interventions: new guidance. Medical Research Council; 2008;337:a1655 .

44. Crosbie JH, Lennon S, Basford JR, McDonough S. Virtual reality in stroke rehabilitation: still more virtual than real. Disabil Rehabil. 2007;29(14):1139-46.

45. Saposnik G, Levin M. Outcome Research Canada Working G. Virtual reality in stroke rehabilitation: a meta-analysis and implications for clinicians. Stroke. 2011;42(5):1380-6. doi: 10.1161/STROKEAHA.110.605451.

46. Laver K, George S, Thomas S, Deutsch J, Crotty M. Virtual Reality for stroke rehabilitation (Review). The Cochrane Collaboration. 2011;7(9). doi:10.1002/14651858

47. Pietrzak E, Cotea C, Pullman S. Using commercial video games for upper limb rehabilitation: is this the way of the future? Top Stroke Rehabil. 2014;21(2);15262.

48. Laver K, Lang K, George S, Tomas S, Deutsch J, Saposnik G, Crotty M. Virtual Reality for stroke rehabilitation (review) [systematic review]. Cochrane Database Syst Rev. 2017(11): Art. No: CD008349. DOI: 10.1002/14651858.CD008349.pub4.

49. Kong KH, Loh YJ, Thia E, Chia A, Ng C, Soh Y et al. Efficacy of a Virtual Reality Commercial Gaming Device in Upper Limb Recovery after Stroke: A Randomized, Controlled Study. Top Stroke Rehabil. 2016;23(5):333-40. doi: 10.1080/10749357.2016.1139796.

50. Coupar F, Pollock A, Legg L, Sackley C, van Vilet P. Home-based therapy programmes for upper limb functional recovery following stroke (review). Cochrane Reviews. 2012(5):1-40. doi: 10.1002/14651858.CD006755.pub2

51. Housman S, Scott K, Reinkensmeyer D. A randomised controlled trial of gravity-supported, computer-enhanced arm exercise for individuals with severe hemiparesis. Neurorehabil Neural Repair. 2009;23(5):505-514.

52. Byl N, Abrams G, Pitsch E, Fedulow I, Kim H, Simkins M et al. Chronic stroke survivors achieve comparable outcomes following virtual task specific repetitive training guided by a wearable robotic orthosis (UL-EXO7) and actual task specific repetitive training guided by a physical therapist. J Hand Therapy. 2013; 26(4):343-51.

53. Tsekleves E, Skordoulis D, Paraskevopoulos I, Kilbride C, Warland A. Personalised stroke rehabilitation intervention using open source 3D software and the Wii Remote Plus. Proc. 9th Intl Conf. Disability, Virtual Reality \& Associated Technologie; 2012 Sept 10-12; Laval, France.

54. Martin S. Patient- and Trial-Specific Barriers to Participation in Cardiovascular Randomized Clinical Trials - ScienceDirect. 2013. doi: 10.1016/j.jacc.2012.10.046.

55. Paraskevopoulos I, Tsekeleves E, Warland A, Kilbride C. Virtual reality based holistic framework: A tool for participatory devlopment of customsied playful therapy sessions for motor rehabilitation. Proceedings of the $8^{\text {th }}$ Intl Conference onVirtual Worlds and Games for Serious Applications (VS-Games). 2016, Sept 7-9; Barcelona, Spain. IEEE 2016. doi: 10 1109/VS-GAMES.2016.7590378.

56. Tsekleves E, Skordoulis D, Paraskevopoulos I, Kilbride C. Wii your health: a low-cost wireless system for home rehabilitation after stroke using Wii remotes and its expansions and blender. Proceedings of the IASTED International Conference Biomedical Engineering (Biomed 2011). ACTA Press; 2011. 723;502-509. 
57. Witmer B, Singer M. Measuring presence in virtual environments: a presence questionnaire. Presence. 1998;7(3):225-240.

58. Schubert T, Friedmann F, Regenbrecht H. The experience of presence: factor analytic insights. Presence. 2001;10(3):266-281.

59. Ashford S, Slade M, Malaprade F, Turner-Stokes L. Evaluation of functional outcome measures for the hemiparetic upper limb: a systematic review. $\mathrm{J}$ Rehabil Med. 2008;40:787-795.

60. Baker K, Cano SJ, Playford ED. Outcome measurement in stroke: a scale selection strategy. Stroke. 2011;42(6):1787-94. doi: 10.1161/STROKEAHA.110.608505.

61. WHO. How to use the ICF: A practical manual for using the international classification of functioning, disability and health (ICF). GEneva: WHO; Oct 2013.

62. Deakin A, Hill H, Pomeroy V. Rough guide to the Fugl-Meyer assessment. Physiotherapy. 2003;89(12):751-763.

63. Fugl-Meyer A, Jääskö L, Leyman I, et al. The post-stroke hemiplegic patient. 1. a method for evaluation of physical performance. Scand J Rehabil Med 1975;7(1):13-31.

64. Penta M, Tesio L, Arnould C,Zanxan A, Thonnard J. The ABILHAND questionnaire as a measure of manual ability in chronic stroke patients: Raschbased validation and relationship to upper limb impairment. Stroke. 2001;32:1627-1634.

65. Lyle R. A performance test for assessment of upper limb function in physical rehabilitation treatmetn and research. Intl J Rehabil Res. 1981:483-492.

66. Uswatte G, Taub E, Morris D, Light K, Thompson P. The Motor Activity Log28: assessing daily use of the hemiparetic arm after stroke. Neurology. 2006 Oct 10;67(7):1189-94. doi: 10.1212/01.wnl.0000238164.90657.c2.

67. Trigg R, Wood V. The validation of the subjective index of physical and social outcome (SIPSO). Clin Rehabil. 2003;17(3):283-9.

68. See J, Dodakian L, Chou C, McKenzie A, Reinkensmeyer D, Cramer S. A standardized approach to the Fugl-Meyer assessment and its implications for clinical trials. Neurorehabil Neural Repair. 2013;27(8):732-41. doi: 10.1177/1545968313491000.

69. Rogers A, Harris T, Victor C, Woodcock A, Limb E, Kerry S et al. Which older people decline participation in a primary care trial of physical activity and why: insights from a mixed methods approach. BMC Geriatrics. 2014;14:46. doi: 10.1186/1471-2318-14-46.

70. Braun V, Clarke V. Using thematic analysis in psychology. Qualitative Research in Psychology. 2006;3(2):77-101. doi: 10.1191/1478088706qp063oa.

71. Creswell J. A concise introduction to mixed methods research. London: Sage; 2015.

72. Lewis GN, Woods C, Rosie JA, McPherson K. Virtual reality games for rehabilitation of people with stroke: perspectives from the users. Disabil Rehabil Assist Technol. 2011;6(5):453-63. doi: 10.3109/17483107.2011.574310.

73. Mat Rosly M, Mat Rosly H, Davis G, Husain R, Hasnan N. Exergaming for individuals with neurological disability: a systematic review. Disabil Rehabil. 201;39(8):727-735. doi: 10.3109/09638288.2016.1161086.

74. Sackett A, Meyvis T, Nelson L, Converse B, Sackett A. You're having fun when time flies: the hedonistic consequences of subjective time progression. Psychol Sci. 2010;21:111-117. doi: 10/1177/0956797609354832. 
75. Iwamoto $\mathrm{Y}$, Hoshiyama M. Alteration of time perception in young and elderly people during jigsaw puzzle tasks with different complexities. Occ Ther Intl. 2011;18:194-2000. doi: 10.1002/oti.322.

76. O'Brien E, Anastasio P, Bushman B. Time crawls when you're not having fun: feeling entitled makes dull tasks drag on. Personality and Social Psychology Bulletin. 2011;37:1287-1296. doi: 10/1177/0956797609354832.

77. Csikszentmihalyi M. Flow. London: Rider; 2002.

78. Mao Y, Roberts S, Pagliaro S, Csikszentmihalyi M, Bonaiuto M. Optimal experience and optimal identitiy: a multinational study of the associations between flow and social identity. Front Psychol. 2016;7(67):1-13.

79. Pageau M, Surgan S. Do we have fun when time flies? J Psychol Res. 2015;20(3):125-135.

80. Abuhamdeh S, Csikszentmihalyi M. The importance of challenge for the enjoyment of intrinsically motivated, goal-directed activities. Pers Soc Psychol Bull. 2012;38(3):317-330.

81. Cirstea MC, Levin MF. Improvement of arm movement patterns and endpoint control depends on type of feedback during practice in stroke survivors. Neurorehabil Neural Rep. 2007;21(5), 398-411.

82. Van Vilet P, Wolf G. Extrinsic feedback for motor learning after stroke: what is the evidence? Disabil Rehabil. 2006;28:831-840.

83. Winstein C. Knowledge of results and motor learning-implications for physical therapy. Phys Ther. 1991;71:140-149.

84. Teixeira-Salmela L, Souza R, Viana R, Laurentino G, Hirochi T, Lambertz K. Higher doses of virtual reality therapy are required to induce changes in upper limb function and quality of life after stroke. Intl J Stroke. 2014;9(Suppl 3):242.

85. Jang S, You S, Hallett M, Cho Y, Park M, Cho S. Cortical reorganization and associated functional motor recovery after virtual reality in patients with chronic stroke: an experimenter-blind preliminary study. Arch Phys Med Rehabil. 2005;86(11), 2218-23.

86. Parker J, Mountain G, Hammerton J. A review of the evidence underpinning the use of visual and auditory feedback for computer technology in post-stroke upper-limb rehabilitation. Disabil Rehabil Assist Tech. 2011:6(6), 465-472.

87. Fetters M, Curry L, Creswell J. Achieving integration in mixed methods designs-principles and practices. Health Services Research. 2013;48(6):21342156.

88. Curry L, Nunez-Smith M. Mixed methods in health sciences research. London: Sage; 2015.

89. Saposnik G, Cohen L, Mamdani M, Pooyania S, Ploughman M, Cheung D et al. Efficacy and safety of non-immersive virtual reality exercising in stroke rehabilitation (EVREST): a randomised, multicentre, single-blind, controlled trial. Lancet Neurol. 2016;15(10):1019-27

90. Henderson A, Korner-Bitensky N, Levin M. Virtual reality in stroke rehabilitation: a systematic review of its effectiveness for upper limb motor recovery. Top Stroke Rehabil. 2007;14(2):52-61. doi: 10.1310/tsr1402-52. 
Table 1: Participant details

\begin{tabular}{|c|c|c|c|c|c|c|c|c|}
\hline $\begin{array}{l}\text { Participant } \\
\text { number } \\
\text { and } \\
\text { pseudonym }\end{array}$ & $\begin{array}{l}\text { Age } \\
\text { (years) }\end{array}$ & Gender & $\begin{array}{l}\text { Time } \\
\text { since } \\
\text { stroke } \\
\text { (months) }\end{array}$ & $\begin{array}{l}\text { Side of } \\
\text { weakness }\end{array}$ & $\begin{array}{l}\text { Modified } \\
\text { Rankin } \\
\text { Score }^{\mathrm{a}}\end{array}$ & $\begin{array}{l}\text { Motricity } \\
\text { Index } \\
\text { score }^{\text {b }} \\
\text { summed } \\
\text { (elbow/ } \\
\text { shoulder) }\end{array}$ & $\begin{array}{l}\text { Hand } \\
\text { dominance }\end{array}$ & $\begin{array}{l}\text { Communication } \\
\text { disorder }\end{array}$ \\
\hline 1: Joe & 64 & Male & 29 & Left & 2 & $\begin{array}{c}50 \\
(25 / 25)\end{array}$ & Right & No \\
\hline 2: Lizzie & 53 & Female & 54 & Right & 3 & $\begin{array}{c}38 \\
(19 / 19)\end{array}$ & Right & Yes \\
\hline 3: Nancy & 65 & Female & 31 & Left & 4 & $\begin{array}{c}28 \\
(14 / 14)\end{array}$ & Right & No \\
\hline 4: George ${ }^{c}$ & 48 & Male & 17 & Right & 3 & $\begin{array}{c}28 \\
(14 / 14) \\
\end{array}$ & Right & Yes \\
\hline 5: Ada & 66 & Female & 46 & Right & 4 & $\begin{array}{c}28 \\
(14 / 14) \\
\end{array}$ & Right & No \\
\hline 6: Esther & 49 & Female & 41 & Left & 2 & $\begin{array}{c}50 \\
(25 / 25)\end{array}$ & Left & No \\
\hline 7: Betty & 67 & Female & 17 & Left & 4 & $\begin{array}{c}28 \\
(14 / 14)\end{array}$ & Right & No \\
\hline $8: \mathrm{Nell}^{\mathrm{d}}$ & 58 & Female & 304 & Right & 2 & $\begin{array}{c}44 \\
(19 / 25)\end{array}$ & Right & No \\
\hline 9: Jenny & 49 & Female & 12 & Left & 3 & $\begin{array}{c}28 \\
(14 / 14) \\
\end{array}$ & Right & No \\
\hline 10: Dora & 60 & Female & 41 & Left & 3 & $\begin{array}{c}28 \\
(14 / 14)\end{array}$ & Right & No \\
\hline 11:Clara & 54 & Female & 114 & Right & 4 & $\begin{array}{c}28 \\
(14 / 14)\end{array}$ & Right & Yes \\
\hline 12: David & 63 & Male & 55 & Left & 2 & $\begin{array}{c}50 \\
(25 / 25)\end{array}$ & Right & No \\
\hline
\end{tabular}

${ }^{a}$ Score of 2 =slight disability, 3 = moderate disability, 4 = moderately-severe disability

${ }^{\mathrm{b}}$ Score of 14 = observable movement, not full range or against gravity. Score of $19=$ full range movement against gravity but not resistance. Score of $25=$ full range movement against resistance but weakness compared to the less affected limb

${ }^{\mathrm{c}}$ Dropped out prior to follow-up (T3), therefore not included in statistical analysis at follow-up but included at other assessment points (T1 and $\mathrm{T} 2$ )

${ }^{\mathrm{d}}$ Dropped out prior to completion of intervention, post-intervention and follow-up therefore not included in statistical analysis of intervention and post-intervention (T2 and T2) but included in baseline analysis (T1). 


\section{Table 2. Integrated feasibility findings}

\begin{tabular}{|c|c|c|c|}
\hline Topic & Quantitative Findings & Qualitative Findings & Level of agreement \\
\hline Safety & $\begin{array}{l}\text { QN1) Thirteen incidents (in } 5 \\
\text { participants) of adverse effects (all non- } \\
\text { serious): } \\
\text { - Mild headache ( } 2 \text { to } 3 \text { on VAS) } \\
\text { in two participants, one occasion } \\
\text { each. } \\
\text { - Shoulder/neck pain ( } 2 \text { to } 5.5 \text { on } \\
\text { VAS) in four participants on } 11 \\
\text { occasions. Eight incidences } \\
\text { consistent with effort and three } \\
\text { occurrences of shoulder } \\
\text { impingement } \\
\text { No incidence of motion sickness, cardio- } \\
\text { respiratory distress, epilepsy, falls or near- } \\
\text { falls }\end{array}$ & $\begin{array}{l}\text { A theme of safety of the PST device was supported by subthemes of: } \\
\text { (QL1) A “good pain" PST device use. } \\
\text { "It's an 'I've been using it' type pain...like when you do something } \\
\text { different. It was a good old fashioned muscle ache as if you have } \\
\text { been working the muscle pretty hard". (David, 63, slight disability) } \\
\text { (QL2) Mental fatigue } \\
\text { "It's a little bit hard, that's why I'm tired...Not tired with my arm you } \\
\text { know, in my brain, because I'm focused" (Betty, 67, moderately- } \\
\text { severe disability }\end{array}$ & Agreement \\
\hline $\begin{array}{l}\text { Ability to use the } \\
\text { PST system }\end{array}$ & $\begin{array}{l}\text { (QN2) All participants were able to use } \\
\text { both activities on the PST system after } \\
\text { individualised calibration. } \\
\text { Mean (SD) time using the PST device } 276 \\
\text { ( } 64.3 \text { ) minutes, range } 175 \text { to } 336 \text { minutes } \\
\text { (target time } 360 \text { minutes). }\end{array}$ & $\begin{array}{l}\text { A theme of ease of use was supported by subthemes of: } \\
\text { (QL3) The PST system being intuitive to use } \\
\text { "I automatically get what to do with this to play the game" (Lizzie, } \\
\text { 53, moderate disability) } \\
\text { (QL4) The necessity of a hands-free system } \\
\text { "Usually I can't do (exercise). No point, for me it's too hard, because } \\
\text { I've got the hand (indicates that has minimal arm movement) At first } \\
\text { I thought 'no! not possible' But then you strapped it to my arm and I } \\
\text { said 'oh (sounds surprised), okay"” (Clara, 54, moderately-severe } \\
\text { disability) } \\
\text { (QL5) Personalisation of activities } \\
\text { "I don't think you need loads (of movement) to play with it. I think, } \\
\text { you know, with minimal arm movement you could give this a go } \\
\text { because I did." (Nancy, 65, moderately severe disability) }\end{array}$ & Agreement \\
\hline
\end{tabular}




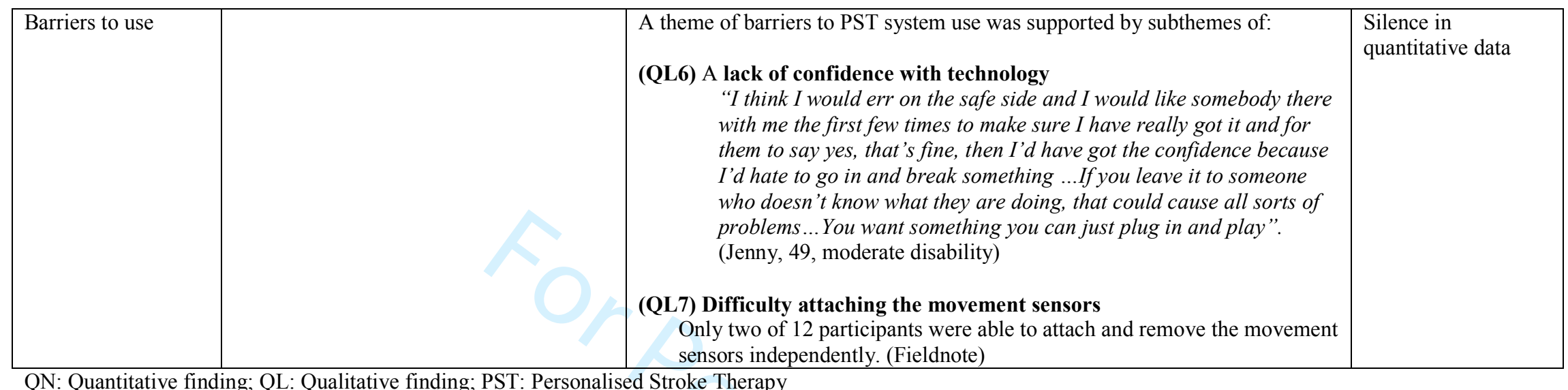

QN: Quantitative finding; QL: Qualitative finding; PST: Personalised Stroke Therapy 


\section{Table 3. Integrated acceptability findings}

\begin{tabular}{|c|c|c|c|}
\hline Topic & Quantitative Findings & Qualitative Findings & $\begin{array}{l}\text { Level of } \\
\text { agreement* }\end{array}$ \\
\hline Enjoyment & $\begin{array}{l}\text { Mean (SD) ratings of enjoyment out of } 10 \\
\text { when using the PST system: } \\
\text { (QN4) Apple-catching game: } 8.1(1.5) \\
\text { (QN5) Virtual therapist application: } 6.8 \\
(2.3)\end{array}$ & $\begin{array}{l}\text { A theme of fun while using the PST system was identified and was underpinned by } \\
\text { subthemes of: } \\
\text { (QL8) Time flying } \\
\text { "It didn't seem like } 40 \text { minutes. It seemed like ten... when you've got a game } \\
\text { and you're so involved in it, time flies. It takes you out of the physical } \\
\text { world so it was fun"” (George, 48, moderate disability) } \\
\text { (QL9) Apple-catching game: fun } \\
\text { "That was really good, it was interesting and fun to play...It's just fun, it's } \\
\text { getting, you know, catching the apples...It was really good. Really } \\
\text { interesting, it was fun to use and play and I enjoyed every minute." (Ada, } \\
\text { 66, moderate severe disability) "I loved the one with the apples! That is so } \\
\text { funny. It's like the apples coming out of the tree you don't know where they } \\
\text { are, so it's like 'oh!' (sounds surprised). I liked the whole package. It was } \\
\text { fun, really good fun." (Lizzie, 53, moderate disability) } \\
\text { (QL10) Virtual therapist: like boring, repetitive physio } \\
\text { "Well (the apple-tree game) is a bit more interesting and less like physio } \\
\text { basically even though I know it is physio, but less like physio, less like } \\
\text { being in hospital and having to do repetitive physio. I'd give it (the virtual } \\
\text { therapist) two out of ten because it was a bit boring." (Dora, 60, moderate } \\
\text { disability) }\end{array}$ & Agreement \\
\hline Level of effort & $\begin{array}{l}\text { Mean (SD) rating of exertion on the BORG } \\
\text { Scale of Perceived Exertion. } \\
\text { (QN6) Apple-catching game: } 11.6(1.3) \\
\text { equating to a descriptor of "fairly light" } \\
\text { (QN7) Virtual therapist application: } 12.9 \\
\text { (1.5), equating to a descriptor of } \\
\text { "somewhat hard" }\end{array}$ & $\begin{array}{l}\text { (QL 11) The virtual therapist application was felt to be the harder activity but both } \\
\text { activities were associated with effort. } \\
\text { "(The virtual therapist) felt arrrgghh. Hard work" (Clara, 54, } \\
\text { moderately-severe disability) } \\
\text { "You still had to strain to do (the apple-catching game). It's not easy" } \\
\text { (Jenny, 49, moderate disability) } \\
\text { (QL12) Suggestions for increased speed of falling apples was a subtheme in those }\end{array}$ & $\begin{array}{l}\text { Partial } \\
\text { agreement }\end{array}$ \\
\hline
\end{tabular}




\begin{tabular}{|c|c|c|}
\hline & $\begin{array}{l}\text { with mild stroke but speed was felt to be at the right level for those with moderately- } \\
\text { severe stroke. } \\
\text { "The apples felt like they were filled with helium, very slowly" (Joe, 63, } \\
\text { slight disability) } \\
\text { "I thought the speed was just right" (Nancy, 65, moderately-severe } \\
\text { disability) } \\
\text { (QL13) Difference in level of difficulty prescribed between researchers } \\
\text { "I had to really move (to catch some of the apples). It depends how (the } \\
\text { apples) were set out. You were particularly cheeky one-day last week and } \\
\text { you put one almost behind the tree trunk sort of thing and I was going } \\
\text { (makes effortful noise), trying to get to it. I thought that was a good one! } \\
\text { But yes it makes you work" (David, 63, slight disability) }\end{array}$ & \\
\hline $\begin{array}{l}\text { Preference for } \\
\text { activity type }\end{array}$ & $\begin{array}{l}\text { (QL14) A preference for the virtual therapist application in those with milder } \\
\text { strokes and the apple-catching game in those with moderate and moderately-severe } \\
\text { stroke. } \\
\text { "You know, if I had the choice of the two I would definitely err in favour of } \\
\text { the virtual teacher. Purely because it is a little more intensive." (David, 63, } \\
\text { slight disability) } \\
\text { "If I had to pick between them, I'd pick the apple game. Well it's a bit more } \\
\text { interesting and less like physio" (Dora, 60, moderate disability) }\end{array}$ & $\begin{array}{l}\text { Silence in } \\
\text { quantitative data }\end{array}$ \\
\hline Feedback & $\begin{array}{l}\text { A theme of motivation through feedback was supported by subthemes of: } \\
\text { (QL15) The apple-tree game as a source of motivating feedback } \\
\text { "I felt the apple one was giving me lots of encouragement. When it called } \\
\text { you 'world class' or 'legend' you thought oh yes, I've cracked this! (The } \\
\text { score) was important. Very important... I could have done with a hint or } \\
\text { two. You know 'lift this, move that' what you needed to do to be world } \\
\text { class... I liked being world class!"' (Nancy, 65, moderately-severe } \\
\text { disability) } \\
\text { (QL16) The need for increased feedback with the virtual therapist application. } \\
\text { "If it maybe said, like when you do it correctly. If you had more of an } \\
\text { indication that yes, what you are doing is correct, it would make you want } \\
\text { to carry on more... Yes, more incentive to say 'well done', 'correct', }\end{array}$ & $\begin{array}{l}\text { Silence in } \\
\text { quantitative data }\end{array}$ \\
\hline
\end{tabular}




\begin{tabular}{|c|c|c|}
\hline & $\begin{array}{l}\text { 'you've done that', 'move on'. For me (it would) make me want to do it } \\
\text { more. Because if you are doing it right, it makes you want to do more...I'm } \\
\text { not competitive but when I see a score of } 54 \text { I think yeah I want to carry } \\
\text { on"' (Jenny, } 49, \text { moderate disability) }\end{array}$ & \\
\hline $\begin{array}{l}\text { Acceptability of } \\
\text { PST system use } \\
\text { in different } \\
\text { settings }\end{array}$ & $\begin{array}{l}\text { A theme of acceptability of use in different settings was underpinned by subthemes } \\
\text { of: } \\
\text { (QL17) Promoting socialisation on-line } \\
\text { "It would be good for someone like me, as speaking to someone new in } \\
\text { person is difficult." (Lizzie, 53, moderate disability) } \\
\text { (QL18) Promoting socialisation with family. } \\
\text { "Now I can play with my children" (George, 48, moderate disability) } \\
\text { (QL19) Wanting to use in home and clinical settings } \\
\text { "I would have used it in hospital without a doubt... Oh yes, I would use it at } \\
\text { home too because I'm seeing improvements" (Jenny, 49, moderate } \\
\text { disability) } \\
\text { (QL20) Concerns about the level of competition were voiced } \\
\text { "People may think 'oh God, you know I'm going to get a whopping again', } \\
\text { and it could actually be a little bit of a regressive thing. It could actually } \\
\text { make you think I'm going to get a caning off this guy again. I'm not really } \\
\text { up for that. It might put them off." (David, 63, slight disability) } \\
\text { (QL21) Telerehabilitation: a source of motivation or 'Big Brother'? } \\
\text { "Some people might look on it with a sort of Big Brother attitude, like I'm } \\
\text { being watched. But on the other hand, some people might sort of go, they } \\
\text { are obviously taking an interest in what I'm doing and they are just sort of } \\
\text { encouraging me, geeing me up a bit, you know, so there are pros and cons } \\
\text { in both directions. Personally I would say, yes, bring it on! It wouldn't } \\
\text { bother me at all. It just shows they are taking an interest in my welfare so } \\
\text { it's going to be helpful for them as well." (David, 63, slight disability) }\end{array}$ & $\begin{array}{l}\text { Silence in } \\
\text { quantitative } \\
\text { data }\end{array}$ \\
\hline $\begin{array}{l}\text { Need for } \\
\text { increased therapy }\end{array}$ & A major theme of not enough therapy, was supported by subthemes of: & $\begin{array}{l}\text { Silence in } \\
\text { quantitative data }\end{array}$ \\
\hline
\end{tabular}




\begin{tabular}{|c|c|c|}
\hline & & $\begin{array}{l}\text { (QL22) "Too many patients" } \\
\text { "I didn't get physio every day and I think that was because of the pressure } \\
\text { of too many patients... Initially I was seen twice a day briefly, OT and } \\
\text { Physio, but that dwindled to just once a day and then, quite often, well it } \\
\text { was just no physio and they would apologise and say I'm afraid your } \\
\text { session has been cancelled because the physio had to go and deal with } \\
\text { somebody else." (Dora, 60, moderate disability) } \\
\text { (QL23) "A focus on legs" (QN18) } \\
\text { "He asked me when I went into rehab, he said 'what is more important to } \\
\text { you? Do you want to focus on your legs or your arm?"” (Nancy, } 65 \\
\text { moderately-severe disability) } \\
\text { (QL24) Wasted time in rehabilitation } \\
\text { "I had more time to spare. There was nothing else to do, there was } \\
\text { nothing. Every morning you had physio and in the afternoon you had } \\
\text { nothing. You either sat down in your bed or slept all day." (Ada, 66, } \\
\text { moderately-severe disability) } \\
\text { (QL25) Being "Abandoned" on discharge home. } \\
\text { "When you go home, locally you just get } 6 \text { weeks and that's it. You are left } \\
\text { to your own devices. Abandoned!" (David, 63, slight disability) }\end{array}$ \\
\hline
\end{tabular}

QN: Quantitative finding; QL: Qualitative finding; PST: Personalised Stroke Therapy 


\section{Table 4. Integrated efficacy findings}

\begin{tabular}{|c|c|c|c|}
\hline Topic & Quantitative Findings & Qualitative Findings & $\begin{array}{l}\text { Level of } \\
\text { agreement* }\end{array}$ \\
\hline $\begin{array}{l}\text { Changes in upper } \\
\text { limb impairment }\end{array}$ & $\begin{array}{l}\text { (QN8) } \\
\text { Score on the FMA-UE increased by } \\
\text { median (IQR) 6 }(8) \text { between T1 and T2 } \\
(\mathrm{p}=0.005) \text {. Reaching MCID in three of } \\
11 \text { participants }(27 \%) \\
\text { Score on the FMA-UE increased by } \\
\text { median (IQR) } 3.5(6.75) \text { from T1 to T3 } \\
(\mathrm{p}=0.033) .\end{array}$ & $\begin{array}{l}\text { (QL26) Improvements in impairments } \\
\text { "I can actually lift my arm up higher and hold it more than I did before" } \\
\text { (Ada, 66, moderately-severe disability) } \\
\text { "What I think the games have done for me, sharpened my perception of } \\
\text { where the hand is...the bigger picture, it has helped me with stamina (Joe, } \\
\text { 64, slight disability) } \\
\text { "Well I felt those muscles being used again. You've heard the old } \\
\text { expression 'God I've got muscles where I never thought I did have', well } \\
\text { I've got muscles where I remember having them!" (David, 63, slight } \\
\text { disability) }\end{array}$ & Agreement \\
\hline $\begin{array}{l}\text { Changes in upper } \\
\text { limb activity }\end{array}$ & $\begin{array}{l}\text { (QN9) } \\
\text { Score on the ABILHAND increased by } \\
\text { median (IQR) } 5(4.5) \text { between T1 and } \\
\text { T2 }(\mathrm{p}=0.005) \\
\text { Score on the ARAT increased by } \\
\text { median (IQR) } 3(6) \text { between T1 and T2 } \\
(\mathrm{p}=0.028) . \text { Reaching MCID in three of } \\
11 \text { participants }(27 \%) \\
\text { Score on the MAL-28 increased by } \\
\text { median (IQR) } 0.28(0.3) \text { between T1 } \\
\text { and T2 (p = 0.006) } \\
\text { Score on the ABILHAND increased by } \\
\text { median (IQR) } 4 \text { (9) between T1 and T3 } \\
(\mathrm{p}=0.107)\end{array}$ & $\begin{array}{l}\text { (QL27) Increased UL functional use } \\
\text { "(The PST device) was making me use it and reminding me it was still } \\
\text { there for use... when I got home I did tend to use my left (hemiplegic) arm } \\
\text { more. It kind of triggered something in my brain... when I went out the } \\
\text { door, usually I would have used my right arm, but I didn't, I held the } \\
\text { handle in my left arm. ...My partner has noticed me using my arm more } \\
\text { spontaneously, opening doors, unwrapping things. Things like that... I feel } \\
\text { this has awakened my brain to the hand." (Esther, 49, slight disability). }\end{array}$ & Agreement \\
\hline
\end{tabular}




\begin{tabular}{|c|c|c|c|}
\hline & $\begin{array}{l}\text { Score on the ARAT increased by } \\
\text { median }(\mathrm{IQR}) 0(4) \text { between T1 and T3 } \\
(\mathrm{p}=0.347) . \text { Reaching MCID in three of } \\
11 \text { participants }(27 \%) \\
\text { Score on the MAL-28 increased by } \\
\text { median }(\mathrm{IQR}) 0.075(0.48) \text { between T1 } \\
\text { and T3 }(\mathrm{p}=0.207)\end{array}$ & & \\
\hline $\begin{array}{l}\text { Changes in } \\
\text { participation }\end{array}$ & $\begin{array}{l}\text { (QN10) } \\
\text { Score on the SIPSO increased by } \\
\text { median }(I Q R) 6(3.5) \text { between T1 and } \\
\text { T2 }(p=0.004) \\
\text { Score on the SIPSO increased by } \\
\text { median }(I Q R) 4.25(1.75) \text { between T1 } \\
\text { and T3 }(p=0.102)\end{array}$ & te & $\begin{array}{l}\text { Silence in } \\
\text { qualitative data }\end{array}$ \\
\hline $\begin{array}{l}\text { Effectiveness of the } \\
\text { activities }\end{array}$ & & $\begin{array}{l}\text { (QL28) The virtual therapist application was considered the more effective } \\
\text { activity } \\
\text { "The apple tree is fun but the other one is like exercise... the robot (the } \\
\text { virtual therapist) is more effective. Better exercise with the robot. More } \\
\text { effective because I do more things like this and this (demonstrates different } \\
\text { arm movements), so it's better exercise with the robot." (Betty 67, } \\
\text { moderately-severe disability) }\end{array}$ & $\begin{array}{l}\text { Silence in } \\
\text { quantitative data }\end{array}$ \\
\hline Psychological effects & & $\begin{array}{l}\text { (QL29) The PST system as a source of hope } \\
\text { "Because everything with a stroke is long winded...this is the first thing } \\
\text { that has given me hope, sort of like the light at the end of the tunnel" } \\
\text { Jenny, 49, moderate disability }\end{array}$ & $\begin{array}{l}\text { Silence in } \\
\text { quantitative data }\end{array}$ \\
\hline Immersive effects & $\begin{array}{l}\text { (QN11) Mean (SD) score on iGroup } \\
\text { Presence Questionnaire } 32.5(21.5) \text { out } \\
\text { of } 85 \text { (with a higher score indicating } \\
\text { greater sense of immersion). }\end{array}$ & $\begin{array}{l}\text { (QL30) Sense of immersion was low and apparent in participant only } \\
\text { "The (virtual therapist) made me feel my arm but not my arm but not my } \\
\text { shoulder blade as I could see my arm but not my shoulder blade" (Lizzie, } \\
\text { 53, moderate disability) }\end{array}$ & Agreement \\
\hline $\begin{array}{l}\text { Telerehabilitation: } \\
\text { effect on exercise } \\
\text { adherence }\end{array}$ & & $\begin{array}{l}\text { A theme of increased exercise adherence with telerehabilitation was noted and } \\
\text { was felt to address reasons for poor adherence with traditional therapy (QL32-34). }\end{array}$ & $\begin{array}{l}\text { Silence in } \\
\text { quantitative data }\end{array}$ \\
\hline
\end{tabular}


QN: Quantitative finding; QL: Qualitative finding; PST: Personalised Stroke Therapy; UL: upper limb; FMA-UE: Fugl-Meyer Assessment; ARAT: Action Research Arm Test; MAL-28: Motor Activity Log -28; SIPSO: Subjective Index of Physical and Social Outcome. MCID: Minimally clinically important difference 
Table 5: Median (IQR) change in impairment, activity and participation between baseline (T1), post-intervention (T2) and follow-up (T3).

\begin{tabular}{|c|c|c|c|c|c|c|c|c|}
\hline \multirow[t]{2}{*}{ Domain } & \multirow[t]{2}{*}{$\begin{array}{l}\text { Outcome } \\
\text { Measure }\end{array}$} & Baseline & $\begin{array}{l}\text { Post- } \\
\text { intervention }\end{array}$ & $\begin{array}{l}\text { Follow- } \\
\text { up }\end{array}$ & \multicolumn{2}{|c|}{$\begin{array}{l}\text { Difference between } \\
\text { baseline and post- } \\
\text { intervention }\end{array}$} & \multicolumn{2}{|c|}{$\begin{array}{l}\text { Difference between } \\
\text { baseline and follow- } \\
\text { up }\end{array}$} \\
\hline & & $\mathrm{T} 1$ & $\mathrm{~T} 2$ & T3 & \multicolumn{2}{|c|}{$\mathrm{T} 1$ to $\mathrm{T} 2$} & \multicolumn{2}{|c|}{ T1 to T3 } \\
\hline \multicolumn{2}{|l|}{$\mathrm{n}$} & 12 & 11 & 10 & \multicolumn{2}{|c|}{11} & \multicolumn{2}{|c|}{10} \\
\hline & & $\begin{array}{c}\text { Median } \\
\text { (IQR) }\end{array}$ & $\begin{array}{c}\text { Median } \\
\text { (IQR) }\end{array}$ & $\begin{array}{c}\text { Median } \\
\text { (IQR) }\end{array}$ & $\begin{array}{c}\text { Median } \\
\text { (IQR) }\end{array}$ & $\mathrm{p}$ value & $\begin{array}{c}\text { Median } \\
\text { (IQR) }\end{array}$ & $\mathrm{p}$ value \\
\hline Impairment & FMA-UE & $29.5(28)$ & $34(33)$ & $\begin{array}{l}34.5 \\
(34)\end{array}$ & $6(8)$ & $0.005^{*}$ & $3.5(6.75)$ & $0.033^{*}$ \\
\hline \multirow[t]{3}{*}{ Activity } & ABILHAND & $24(16)$ & $28(17)$ & $27(14)$ & $5(4.5)$ & $0.005 *$ & $4(9)$ & 0.107 \\
\hline & ARAT & $5.5(24)$ & $12(32)$ & $7(32)$ & $3(6)$ & $0.028^{*}$ & $0(4)$ & 0.347 \\
\hline & MAL-28 & $1.11(2.7)$ & $1.7(3.14)$ & $\begin{array}{l}1.9 \\
(3.35)\end{array}$ & $\begin{array}{l}0.28 \\
(0.3)\end{array}$ & $0.006^{*}$ & $\begin{array}{l}0.075 \\
(0.48)\end{array}$ & 0.207 \\
\hline Participation & SIPSO & $25.5(11)$ & $30(11)$ & $\begin{array}{l}28.5 \\
(16)\end{array}$ & $6(3.5)$ & $0.004 *$ & $\begin{array}{l}4.25 \\
(1.75)\end{array}$ & 0.102 \\
\hline
\end{tabular}

FMA-UE: Fugl-Meyer Assessment; ARAT: Action Research Arm Test; MAL-28: Motor Activity Log 28; SIPSO: Subjective Index of Physical and Social Outcome *significant change. 